\title{
Muscidifurax raptor GIRAULT \& SANDERS, 1910 E Pachycrepoideus vindemiae RONDANI, 1875 (HYMENOPTERA: PTEROMALIDAE) EM PUPAS DE Sarcophagula occidua FABRICIUS, 1794 (DIPTERA: SARCOPHAGIDAE) EM FEZES BOVINAS NO BRASIL
}

\author{
Muscidifurax raptor GIRAULT \& SANDERS, 1910 AND Pachycrepoideus vindemiae RONDANI, 1875 \\ (HYMENOPTERA: PTEROMALIDAE) IN PUPAES OF Sarcophagula occidua FABRICIUS, 1794 \\ (DIPTERA: SARCOPHAGIDAE) IN CATLLE DUNG IN BRAZIL
}

Carlos Henrique Marchiori ${ }^{1}$ Fábio Fernandes Teixeira ${ }^{2}$ Cláudio Gonçalves da Silva ${ }^{2}$ Cristiane Isabel da Silva Vieira ${ }^{2}$ Angélica Maria Penteado-Dias ${ }^{3}$

\section{- NOTA -}

RESUMO

A primeira ocorrência dos parasitóides Muscidifurax raptor Girault \& Sanders, 1910 e Pachycrepoideus vindemiae Rondani, 1875 em pupários de Sarcophagula occidua Fabricius, 1794 em fezes bovinas no Brasil é relatada. O monitoramento foi realizado na Chácara Vilela, em ItumbiaraGO. Quinzenalmente, 10 amostras de esterco bovino foram colhidas aleatoriamente nas pastagens e transportadas para o laboratório do Instituto Luterano de Ensino Superior de Itumbiara-GO. Artrópodes foram extraídos dessas amostras cinco dias após a coleta no campo, submergindo as amostras em baldes contendo água. As pupas muscóides foram retiradas com peneira e acondicionadas, individualmente, em cápsulas de gelatina até sua emergência ou a de parasitóides. A porcentagem de parasitoidismo foi de $0,47 \%$.

Palavras-chave: Muscidifurax raptor, Pachycrepoideus vindemiae, Sarcophagula occidua, primeira ocorrência, parasitóide: hospedeiro.

\section{SUMMARY}

The first occurrence of parasitoids Muscidifurax raptor and Pachycrepoideus vindemiae in puparios of
Sarcophagula occidua in cow dung in Brazil is reported. The experiment was undertaken at "Chacara Vilela" located in the county of Itumbiara, GO, Brazil. Ten samples of bovine dung were collected every fifteen days. "Instituto Luterano de Ensino Superior de Itumbiara-GO”. They were taken to the laboratory and the arthropods were extracted by water flotation five days after the collection. The pupae were then individually placed in transparent gelatin capsules until the emergence of the adult flies or their parasitoids. The percentage of parasitizing of $0.47 \%$.

Key words: Muscidifurax raptor, Pachycrepoideus vindemiae, Sarcophagula occidua, first occurrence, parasitoid:host.

A família Pteromalidae (Hymenoptera, Chalcidoidea) constitui-se de um grande número de espécies parasitóides, muitas das quais têm importância significativa no controle biológico de muscóides sinantrópicos (RUEDA \& AXTELL, 1985). Eles podem ser solitários e gregários, ectoparasitóides ou endoparasitóides, parasitóides

\footnotetext{
${ }^{1}$ Professor Doutor, Departamento de Biologia do Instituto Luterano de Ensino Superior de Itumbiara-GO, ULBRA, Av. Beira Rio, 1001, Bairro Nova Aurora, 75500-000, Itumbiara, Goiás. E-mail: pesquisa@ns.Itumbiara.com.br. Autor para correspondência.

${ }^{2}$ Aluno do Departamento de Biologia do Instituto Luterano de Ensino Superior de Itumbiara-GO, ULBRA.

${ }^{3}$ Professor Doutor, Departamento de Ecologia e Biologia Evolutiva da Universidade Federal de São Carlos- CP 676, São Carlos, São Paulo, 13565-905. E-mail: agnelica@ power.ufscar.br.
} 
primários ou secundários, coinobiontes ou idiobiontes. A maioria é idiobionte, e muitos se desenvolvem como ectoparasitóides em larvas ou pupários de Diptera, Coleoptera, Hymenoptera, Lepidoptera e Siphonaptera (GAULD \& BOLTON, 1988).

Muscidifurax raptor comporta-se como ectoparasitóide solitário de pupas de muscóides. Essa espécie é a mais abundante em pupas de Musca domestica (Linnaeus, 1785) e associada a fezes de galinha, de bovinos e caprinos no Estado da Carolina (RUEDA \& AXTELL, 1985). Muscidifurax raptor foi encontrado em pupas de Calliphoridae, Fanniidae, Muscidae e Sarcophagidae. Essa espécie é encontrada nas Américas Central, do Norte do Sul, África e Europa (RUEDA \& AXTELL, 1985). Pachycrepoideus vindemiae é considerado um parasitóide solitário de dípteros pertencentes às famílias Anthomyiidae, Calliphoridae, Drosophilidae, Fanniidae, Muscidae, Tachinidae, Tephritidae, entre outras. Esta espécie apresenta distribuição cosmopolita (GRISSELL \& SCHAUFF, 1990).

Sarcophagula occidua é encontrada na Argentina e Brasil, sendo que pode estar também presente em fezes humanas e de eqüinos (DIAZ \& GALLARDO, 1996).

O objetivo desta comunicação científica é registrar a primeira ocorrência no Brasil, dos parasitóides Muscidifurax raptor e Pachycrepoideus vindemiae em pupários de Sarcophagula occidua em fezes bovinas coletadas nos currais em Itumbiara, GO.

A coleta de pupas muscóides foi realizada em fezes depositadas em currais de bovinos na Chácara Vilela, situada no bairro Village, distante 5 quilômetros do centro de Itumbiara-GO, $\left(18^{\circ} 25^{\prime} \mathrm{S}\right.$ e $49^{\circ} 13^{\prime} \mathrm{W}$ ), às margens do rio Paranaíba. A chácara possui uma área de aproximadamente 29 hectares, com 50 cabeças de gado bovino. Durante o período chuvoso, o gado é tratado somente com capim e durante a seca são fornecidos aos animais alimentos à base de ração $\left(\right.$ Tapuia $^{\mathrm{R}}$ ), resíduo de milho, canade-açúcar e capim napier (Pennisetum purpureum (Schum, 1902). Os dejetos presentes nos currais (dois currais) foram recolhidos e amontados numa esterqueira próxima ( $4 \mathrm{~m}$ de comprimento e $3 \mathrm{~m}$ de largura). Este substrato serviu para a criação de várias espécies de moscas. Realizou-se o recolhimento dos artrópodes quinzenalmente, nos montes de esterco com mais de quinze dias de permanência na esterqueira. Foram retiradas 10 bacias plásticas ( $40 \mathrm{~cm}$ de diâmetro e $12 \mathrm{~cm}$ de altura) de esterco. As pupas muscóides, obtidas pelo método de flutuação (SPILLER, 1966), foram armazenadas em cápsulas de gelatina (número 00), onde se aguardou emergência das moscas e/ou dos parasitóides. Os adultos obtidos por esse processo foram contados e identificados. O monitoramento foi realizado de junho a dezembro de 1999. A porcentagem de parasitoidismo em Sarcophagula occidua foi calculada através do número de parasitóides emergidos relacionado ao número total de pupários coletados. Os parasitóides foram identificados pela Dra. Angélica Maria PenteadoDias, da Universidade Federal de São Carlos.

Após 14 coletas, obtiveram-se 3169 pupas de Sarcophagula occidua, sendo que delas emergiram 1975 adultos muscóides e 15 parasitóides. Cerca de 37\% (1179) de pupários de sarcofagídeo não viabilizou a emergência de imagos muscóides ou de pteromalídeos. Provavelmente isso se deve ao tipo de metodologia empregada ou à época de coletas realizadas. Dos 15 parasitóides obtidos, foram identificados 4 espécimes de Muscidifurax raptor e 11 espécimes de Pachycrepoideus vindemiae. A porcentagem total de parasitoidismo foi de $0,47 \%$. O baixo percentual de parasitoidismo pode ser decorrente da alta taxa de pupas muscóides que não originaram adultos. Nesse estudo, não foi observado multiparasitoidismo em pupários de Sarcophagula occidua. Muscidifurax raptor e Pachycrepoideus vindemiae comportaramse como parasitóides solitários de pupários de Sarcophagula occidua.

\section{REFERÊNCIAS BIBLIOGRÁFICAS}

DÍAZ, N., GALLARDO, F. Sobre cinipoideos del Brasil, parasitoides de dipteros estercoleros (Hymenoptera: Cynipoidea). Rev Soc Entomol Argent., v.55, p.27-129, 1996.

GAULD, I.D., BOLTON, B. The hymenoptera. New York : Oxford University, 1988. 331p.

GRISSELL, E.E, SCHAUFF, M.E. A handbook of the families of Nearctic Chalcidoidea (Hymenoptera). Entomol Soc Was, v.41, p.1-85, 1990.

RUEDA, L.M., AXTELL, R.C. "Guide to common species of pupal parasites (Hymenoptera: Pteromalidae) of the house fly and other muscoid flies associated with poultry and livestock manure." North Carolina : North Carolina Agricultural Research Service, 1985. 88p. (Technical Bulletin).

SPILLER, D. House flies. In: SMITH, C.N. Insect colonization and mass production. New York : Academic, 1966. Cap. 6. p.203-225. 